\title{
R\&D Tax Incentives: How Do They Impact Portuguese Start-ups?
}

\author{
Luís Ferreira ${ }^{1,}$ Alexandra Xavier ${ }^{1,}$ Daniel Polónia ${ }^{2}$
}

\begin{abstract}
In this work, a comparison between start-up companies' performance is made based on the way they use the Portuguese R\&D tax credit program. From the analysis of the results, it is possible to verify that companies that benefit from this program have a distinct behavior from those that do not, either in what regards financial performance, the weight of the intangible assets in the company or in what regards the quality and value added of the jobs created. It is also possible to find that beneficiary companies mix the tax credits with the use of European, national and regional grants, thus mixing the funding available to support their Research, Development and Innovation activities.
\end{abstract}

Keywords: SIFIDE; grants; start-up; Portugal; performance

Submitted: Jun 29 2018 / Approved: December $14^{\text {th }}, 2018$

\section{Introduction}

There is a growing awareness, both by policy makers and the business sector, that Research, Development and Innovation (RDI) activities are key factors for future economic growth and sustainability. This has led countries in recent years to adopt support financing programs for such activities. These support programs usually of two types: direct support (mostly grants) and indirect support (mainly tax incentives) that can be used exclusively or cumulatively by the companies. In OECD and EU countries the tax incentives are applied generally in the form of a tax credit that is calculated with a rate applied to the companies RDI approved expenses and, in recent years, the measurement of the total RDI support to companies has verified that the tax incentive programs have been increasing their relative importance in the total volume of public support to the business sector over the direct support programs (OECD, 2018). In the Portuguese case, the RDI landscape is characterized by the existence of direct support programs, mostly provided by European programs such as Horizon 2020 and national and regional development and cohesion funds that, in the last 10 years, have been placing a special emphasis on innovation and internationalization of companies. In what concerns indirect support programs, the Portuguese government has in place since 1997 a Tax Credit Program, the SIFIDE (Fiscal Incentive System supporting R\&D in Enterprises) Program that each year provides tax deductions to the expenses made on R\&D activities.

A study performed in Portugal for the period 1998 thru 2010 (Carvalho, 2013), highlighted a sustainable growth of the public financing to business R\&D in Portugal, and also reported an increase in the relative importance of the tax incentives over direct support. In Spain, (Corchuelo \& Martínez-Ros, 2010) noticed that the knowledge on tax incentive programs was scarce by most companies, with SMEs with innovative capacity using them together with government grants. (Busom, Corchuelo, \& Martínez-Ros, 2014) have reported that grants are more suitable for firms that do not have previous R\&D activity and especially to young and knowledge intensive firms whereas tax incentives help firms that already are performing $R \& D$ to continue or increase their innovative activities. Also it has already been found that tax credits have a higher effect in service start-up companies (Castellacci \& Lie, 2015), but a balance between tax credits and grants must be reached in order to adjust the incentives to an optimal level (Noked, 2014). Finally, considering the mix between grants and tax benefits, (Radas, Anić, Tafro, \& Wagner, 2015) report that they make a difference in SMEs, independently of the approach to the mix chosen by companies, although it is suggested that direct support is more suited to SMEs.

With this knowledge, and considering that the Portuguese entrepreneurial landscape has, in the recent years, seen the appearance of multiple technological start-ups, either promoted by qualified independent entrepreneurs or by universities and research institutes, that try to expand revenue sources by pipelining R\&D thru start-ups in incubators, it is important to understand how technological startups (less than 10 years of age) companies use these support schemes, measuring how companies use the $\mathrm{R} \& \mathrm{D}$ tax credits and assessing its influence in competitiveness, as measured by a set of nine performance indicators.

As mentioned before, these questions arise from the fact that little attention was paid in literature to the Portuguese case (Carvalho, 2013; Direção Geral da Estatística da Ciência e da Educação, 2016) and the fact that, in OECD, little analysis on how the R\&D tax schemes are being used, although tax generosity has been extensively studied (Baliamoune-Lutz, 2015; Thomson, 2012). Also, very few studies can be found on how the grants leverage R\&D and innovation (Silva, 2014), although the last two Multi-annual Financial Frameworks (MFF) of the European Union have been devoted to R\&D\&I, either through direct RTD grants or through regional development funding, managed by national and regional development agencies.

(1) INESCTEC - Institute for Systems and Computer Engineering, Technology and Science, Faculdade de Engenharia da Universidade do Porto, Porto, Portugal. (2) Governance, Competitiveness and Public Policy Research Group, Department of Economics, Management, Industrial Engineering and Tourism, University of Aveiro, Campus Universitário de Santiago, Aveiro; Portugal.

*Corresponding author: dpolonia@ua.pt 


\section{Method}

\section{Subjects or Participants}

Since Portugal has one of the most competitive R\&D tax credit schemes of OECD and considering the existing literature on the subject in what concerns small, technology oriented companies, the study focused on companies with less than 10 year of age and with a number of employees between 2 and 250, that operate in manufacturing and services knowledge intensive areas, as defined by the Eurostat (2018).

The study aims to understand how these companies use the policy mix provided by grants and tax credits to $\mathrm{R} \& \mathrm{D}$ and create a typical profile of companies during the last 5 years.

For that, information regarding companies provided by the SABI database (Bureau Van Dijk, 2018) was collected, systematizing information on companies in Portugal regarding its Fiscal Identification Number (NIF), its status and foundation date and, for the fiscal year of 2016, the turnover, the EBITDA, the total assets, the intangible assets, the grants received, the added value, the export volume, the total yearly expenditure on salaries and the number of employees.

Information on the use of tax credits for the years 2012 thru 2016 is made publicly available by the Portuguese Government, and it includes the tax credits claimed by companies, following the emission of a tax credit voucher, awarded by the National Innovation Agency, to companies that fulfilled the requirements of SIFIDE II and that can be used by the companies in the following five fiscal years. Companies are identified by their Fiscal Identification Number (NIF) (systematized untreated data available in https://goo.gl/A8Sdp9 ).

Crossing the information on the two sources, it was possible to identify 1523 companies that benefited at least once from SIFIDE between 2012 and 2016; of these companies, 170 cumulatively fulfilled the following requirements: have a financial statement available for the year 2016, have an incorporation date between 01/01/2007 and $31 / 12 / 2016$, have between 3 and 250 employees, have an operating revenue in the year 2016 of less than $50.000 .000 €$ and have a balance sheet in the year 2016 of less than $43.000 .000 €$. It should be noted that the last three requirements correspond to the European Commission requirements for a company to be considered an SME. As a final filter, were selected only the companies that have a NACE code corresponding to manufacturing and services knowledge intensive areas as defined by the Eurostat. Of the 170 companies, 152 benefited from operating grants in at least one of the five years, whereas 18 did not.

Doing the same exercise for companies that did not benefit from SIFIDE between 2012 and 2016, it was identified the 10289 remaining Portuguese companies had fulfilled the same characteristics cumulatively but did not benefit from SIFIDE in the last 5 years. Of these, 5289 benefited from operating grants in at least one of the five years, whereas 5000 did not.

\section{Design}

Based on the use of tax credits by the companies in the last five years, it is possible to create two independent groups of companies:

0 - Companies that did not benefit from SIFIDE tax credits in the years 2012 thru 2016

1 - Companies that benefited from SIFIDE tax credits in the years 2012 thru 2016

So that the impact can be measured, it is necessary to have key performance indicators. Although there is no consensus on how the performance of companies can be measured, (Lumpkin \& Ireland, 1988) included in the financial strengths that a young company should have, its profitability and the debt level that it presents, along with the management team skills and the marketability and uniqueness of the product/service.

In a more systematic approach, the measurements made rely on the assumption that companies must base their strengths in its financial profitability and productivity (Guo, Hotchkiss, \& Song, 2011; Jain \& Kini, 1994; Kaplan, 1989), presenting an effective commercial performance (Wiggins \& Gibson, 2003) and leveraging their innovation on tax credits and grants provided to support innovation and technological leadership (Howell, 2017) at national and European level. Further measurement can be done so that it is verified that ensuring that each job created presents an added value to the entrepreneurial process (Sauermann, 2016) with reasonable salaries (Botti, 2013) and with an external market orientation (Rose \& Shoham, 2002).

For each group, in order to measure the performance of the companies involved, a set of indicators was developed based on company data for the year 2016:

1. Commercial performance, evaluated as the ratio between the turnover and the number of employees (01COMPER);

2. Profitability, evaluated as the ratio between the EBITDA and Turnover (02PROFIT);

3. Productivity on the use of the total assets, evaluated as the ratio between the EBITDA and the Total Assets (03PRODASSE);

4. Weight of intangible assets, evaluated as the ratio between the Intangible Assets and the Total Assets of the organization (04PRODINTA);

5. Dependency on private or public grants, evaluated as the ratio between the sum of the Grants received in the last 5 years and the Turnover in 2016 (05GRANTS);

6. Dependency on SIFIDE, evaluated as the ratio between the sum of SIFIDE tax returns in the last 5 years and the Turnover in 2016 (06SIFIDE); 
7. Quality of the jobs created, evaluated as the ratio between the total yearly expenditure on salaries and the number of employees (07 EXPEREMP);

8. Value added per employees, evaluated as the ratio between the total added value of the company and the number of employees (08 VAPEREMP);

9. Openness of the companies to external markets, evaluated as the ratio between Exports and the Turnover (09 EXPORTURN).

Based on the fiscal number of each company, data tables were created based on the SIFIDE data and on the data available in SABI databases. This information was then crossed, and the SPSS ready .sav files were then created.

\section{Results}

Since the results provided by the dependent variables are a quantitative variable, and since the way that firms can use the tax credits leads to a nominal independent variable that defines two independent groups, where it is intended to know if the average values of the nine performance indicators are different among the two groups, a one way ANOVA test is applied.

The two groups come from a normally distributed population, where all the nine variables follow a normal distribution in all the two groups.

In the two groups, there is no relationship between its members, as such there is independence of the samples.

The companies with no tax credits registered in the last five years are a large sample (100 companies randomly chosen from a set of
10289 companies) and the companies that benefited from tax credits in the last five years is also a large sample (100 companies randomly chosen from a set of 170 companies). In these two cases the Central Limit Theorem can be applied. However, after testing for normality applying the Shapiro-Wilk test to this case, the result rejects the null hypothesis of the existence of a normal distribution and thus it is not possible to use the one-way ANOVA test.

Instead, it is used the Mann Whitney U Test for 2 independent samples.

Once again, using the initial hypothesis, it is questioned if the way that the companies use the R\&D tax credits has influence in its competitiveness, as measured by a set of nine performance indicators.

Since the way that companies use the R\&D incentives is an ordinal qualitative variable that ranges from 0 (did not benefit from tax credits in the last five years) to 1 (benefited from tax credits in the last five years), and since it defines two independent groups, it is applied the Mann Whiney U test.

The independence of the sample is guaranteed, since the companies that belong to each group do not have any relationship between them.

As a null hypothesis, it is defined the following:

H0: The two groups of companies, defined by the way they use R\&D tax credits, have the same competitiveness performance indicators.

From the results of the test, it is possible to reject the null hypothesis in all cases, except for the one related to the productivity of assets (03PRODASSE), defined as the ratio between the EBITDA and the Total Assets of the company, as shown in Table 1.

Table 1. Statistical test of the considered variables.

\begin{tabular}{|c|c|c|c|c|c|c|c|c|c|}
\hline & O1COMPER & 02PROFIT & 03PRODASSE & 04PRODINTA & 05GRANTS & 06SIFIDE & 07EXPEREMP & O8VAPEREMP & 09EXPORTURN \\
\hline Mann-Whitney U & 1406.000 & 3469.000 & 4866.000 & 2909.000 & 1557.000 & .000 & 461.000 & 325.000 & 1161.000 \\
\hline Wilcoxon W & 6456.000 & 8519.000 & 9916.000 & 7959.000 & 6607.000 & 5050.000 & 5511.000 & 5375.000 & 6211.000 \\
\hline Z & -8.782 & -3.741 & -.327 & -5.407 & -8.428 & -13.060 & -11.091 & -11.423 & -9.966 \\
\hline
\end{tabular}

Grouping Variable: BENEF

By rejecting the null hypothesis in all but one case, it is validated in all the other eight remaining indicators that the way the R\&D incentives are used affects the competitiveness performance indicators of the companies.

In all cases, it is possible to find that companies that used SIFIDE tax credit in the last five years, have a tendency to become more competitive.

In more detail,
A Mann-Whitney $U$ test was run to determine if there were differences in commercial performance score between companies that did and did not benefit from SIFIDE in the last five years. Distributions of the commercial performance (01COMPER) scores for companies that did and did not benefit from SIFIDE in the last five years were not similar, as assessed by visual inspection. Commercial performance (01COMPER) scores for companies that did benefit from SIFIDE in the last five years (mean rank $=136.44$ ) were statistically significantly higher than for those who did not (mean rank $=64.56$ ), $U=$ 1406.000, $z=-8.782$., $p<.001$. Median commercial performance 
(01COMPER) score was statistically significantly higher for companies that did benefit from SIFIDE in the last five years (71.805) than for those who did not (36.688).

A Mann-Whitney $U$ test was run to determine if there were differences in profitability score between companies that did and did not benefit from SIFIDE in the last five years. Distributions of the profitability (02PROFIT) scores for companies that did and did not benefit from SIFIDE in the last five years were not similar, as assessed by visual inspection. Profitability (02PROFIT) scores for companies that did benefit from SIFIDE in the last five years (mean rank = 136.44) were statistically significantly higher than for those who did not (mean rank =64.56), $U=3469.000, z=-3.741 ., p<.001$. Median profitability (02PROFIT) score was statistically significantly higher for companies that did benefit from SIFIDE in the last five years $(0.115)$ than for those who did not (0.090).

A Mann-Whitney $U$ test was run to determine if there were differences in the productivity of assets. Distributions of the productivity of assets (03PRODASSE) scores for companies that did and did not benefit from SIFIDE in the last five years were similar, as assessed by visual inspection. Median productivity of assets (03PRODASSE) score was not statistically significantly different between companies that did benefit from SIFIDE in the last five years (mean rank = 99.16) were statistically significantly higher than for those who did not (mean rank $=101.84), U=4866.000, z=-0.327, p=.743$. Median productivity of assets (03PRODASSE) score for companies that did benefit from SIFIDE in the last five years $(0.136)$ and for those who did not (0.142) was not statistically different.

A Mann-Whitney $U$ test was run to determine if there were differences in the weight of intangible assets in the company score between companies that did and did not benefit from SIFIDE in the last five years. Distributions of the weight of intangible assets in the company (04PRODINTA) scores for companies that did and did not benefit from SIFIDE in the last five years were not similar, as assessed by visual inspection. The weight of intangible assets in the company (04PRODINTA) scores for companies that did benefit from SIFIDE in the last five years (mean rank $=121.41$ ) were statistically significantly higher than for those who did not (mean rank $=79.59$ ), $U=$ 2909.000, $z=-5.407, p<.001$. Median weight of intangible assets in the company (04PRODINTA) score was statistically significantly higher for companies that did benefit from SIFIDE in the last five years (0.004) than for those who did not (0.000).

A Mann-Whitney $U$ test was run to determine if there were differences in the dependency on private or public grants score between companies that did and did not benefit from SIFIDE in the last five years. Distributions of the dependency on private or public grants (05GRANTS) scores for companies that did and did not benefit from SIFIDE in the last five years were not similar, as assessed by visual inspection. The dependency on private or public grants (05GRANTS) scores for companies that did benefit from SIFIDE in the last five years (mean rank $=134.93$ ) were statistically significantly higher than for those who did not (mean rank=66.07), $U=1557.000, z=-8.428, p<.001$.
Median dependency on private or public grants (05GRANTS) score was statistically significantly higher for companies that did benefit from SIFIDE in the last five years (0.106) than for those who did not (0.011).

A Mann-Whitney $U$ test was run to determine if there were differences in the dependency on tax credits score between companies that did and did not benefit from SIFIDE in the last five years. Distributions of the dependency on tax credits (06SIFIDE) scores for companies that did and did not benefit from SIFIDE in the last five years were not similar, as assessed by visual inspection. The dependency on tax credits (06SIFIDE) scores for companies that did benefit from SIFIDE in the last five years (mean rank $=150.50$ ) were statistically significantly higher than for those who did not (mean rank $=50.50), U=$ $0.000, z=-13.060 ., p<.001$. Median dependency on tax credits (06SIFIDE) score was statistically significantly higher for companies that did benefit from SIFIDE in the last five years (0.029) than for those who did not (0.000).

A Mann-Whitney $U$ test was run to determine if there were differences in the quality of jobs created score between companies that did and did not benefit from SIFIDE in the last five years. Distributions of the quality of jobs created (07EXPEREMP) scores for companies that did and did not benefit from SIFIDE in the last five years were not similar, as assessed by visual inspection. The quality of jobs created (07EXPEREMP) scores for companies that did benefit from SIFIDE in the last five years (mean rank $=145.89$ ) were statistically significantly higher than for those who did not (mean rank $=55.11), U=$ $461.000, z=-11.091 ., p<.001$. Median quality of jobs created (07EXPEREMP) score was statistically significantly higher for companies that did benefit from SIFIDE in the last five years (24.752) than for those who did not (13.340).

A Mann-Whitney $U$ test was run to determine if there were differences in the value added per employee score between companies that did and did not benefit from SIFIDE in the last five years. Distributions of the value added per employee (08VAPEREMP) scores for companies that did and did not benefit from SIFIDE in the last five years were not similar, as assessed by visual inspection. The value added per employee (08VAPEREMP) scores for companies that did benefit from SIFIDE in the last five years (mean rank = 147.25) were statistically significantly higher than for those who did not (mean rank = 53.74), $U=461.000, z=-.11 .423, p<.001$. Median value added per employee (08VAPEREMP) score was statistically significantly higher for companies that did benefit from SIFIDE in the last five years (35.027) than for those who did not (18.068).

A Mann-Whitney $U$ test was run to determine if there were differences in the openness of the companies to external markets score between companies that did and did not benefit from SIFIDE in the last five years. Distributions of the openness of the companies to external markets (09EXPORTURN) scores for companies that did and did not benefit from SIFIDE in the last five years were not similar, as assessed by visual inspection. The openness of the companies to external markets (09EXPORTURN) scores for companies that did benefit from 
SIFIDE in the last five years (mean rank $=138.89$ ) were statistically significantly higher than for those who did not (mean rank = 62.11), $U=1161.000, z=-9.966, p<.001$. Median openness of the companies to external markets (09EXPORTURN) score was statistically significantly higher for companies that did benefit from SIFIDE in the last five years $(0.260)$ than for those who did not $(0.000)$.

\section{Discussion}

Considering the results presented previously and the null hypothesis framed initially (H0: The two groups of companies, defined by the way they use R\&D tax credits, have the same competitiveness performance indicators), although it is not possible to categorically reject it, it is possible to verify that the companies that benefited from tax incentives present a clearly distinct behavior from the companies that did not, not only in what regards the mix they make with the grants available (05GRANTS) but also in what regards financial performance (01COMPER and 02PROFIT). Furthermore, they present a clearly distinctive behavior in what regards the importance that the intangible assets present when weighted against the total assets of the company (04PRODINTA) or in what regards the quality (07EXPEREMP) and value-added (08VAPEREMP) of the jobs created, with companies clearly aiming at external markets (09EXPORTURN).

Framing the results obtained against the literature review performed earlier, it is clear that most companies that use the $\mathrm{R} \& \mathrm{D}$ tax incentives, also use the grants provided by the European, national and regional funding mechanisms. Also, the companies that benefit from SIFIDE show a better performance in what regards the ratio between the total yearly expenditure on salaries and the number of employees, presenting evidence that SIFIDE beneficiary companies have better paying jobs, thus retaining talented people in order to perform non-routine, value added work. Although the results are clearly favorable in what relates to the results shown by the SIFIDE beneficiaries, it must be stressed that the values relate to the median obtained as a result of the application of the Mann Whitney $U$ test and not the mean values that could be obtained if the normality test had been successful and the one-way ANOVA test. Also, and since we are dealing with public policies that usually lack the technical expertise in the evaluation of the R\&D investments, rather relying on the financial demonstration of the investments made, there can be a bias in the results shown by the SIFIDE beneficiary companies, thus resulting in a "the need to show" effect propelled by the need to demonstrate the financial results of the investments made.

As a final note for future research, and since there are multiple $R \& D$ tax credit schemes in OECD, probably a comparison between the effectiveness of the schemes could be performed, based on the results that the beneficiary start-up companies in each country present in their financial results.

\section{References}

Baliamoune-Lutz, M. (2015). Taxes and entrepreneurship in OECD countries. Contemporary Economic Policy, 33(2), 369-380. https:// doi.org/10.1111/coep.12079
Botti, S. (2013). Expert evaluation network Job creation as an indicator of outcomes in ERDF programmes Expert evaluation network delivering policy analysis on the performance of Cohesion policy 2007-2013 $2013 \mathrm{Job}$ creation as an indicator of outcomes in ERDF programmes Syn. Retrieved from http://ec.europa.eu/regional_policy/sources/docgener/evaluation/ pdf/eval2007/job_creation/evalnet_task1_job_creation_synthesis.pdf

Bureau Van Dijk. (2018). Sabi - Spain and Portugal financial company information and business intelligence - BvD. Retrieved June 4, 2018, from https://www.bvdinfo.com/en-us/our-products/companyinformation/national-products/sabi

Busom, I., Corchuelo, B., \& Martínez-Ros, E. (2014). Tax incentives... or subsidies for business R\&D? Small Business Economics, 43(3), 571596. https://doi.org/10.1007/s11187-014-9569-1

Carvalho, A. (2013). Financiamento público à I\&D empresarial em Portugal. Notas Económicas, (37), 34-49. Retrieved from https:// ideas.repec.org/a/gmf/journl/y2013i37p34-49.html

Castellacci, F., \& Lie, C. M. (2015). Do the effects of R\&D tax credits vary across industries? A meta-regression analysis. Research Policy, 44(4), 819-832. https://doi.org/10.1016/j.respol.2015.01.010

Corchuelo, M. B., \& Martínez-Ros, E. (2010). Who benefits from R\&D tax policy? Cuadernos de Economía y Dirección de La Empresa, 13(45), 145-170. https://doi.org/10.1016/S1138-5758(10)70027-X

Direção Geral da Estatística da Ciência e da Educação. (2016). Direção-Geral de Estatísticas da Educação e Ciência. Inquérito ao Potencial Cientifico e Tecnológico Nacional 2016. Retrieved from http:// www.dgeec.mec.pt/np4/206/

Eurostat. (2018). Eurostat indicators on High-tech industry and Knowledge - intensive services. Retrieved June 19, 2018, from http:// ec.europa.eu/eurostat/cache/metadata/Annexes/htec_esms_an3.pdf

Guo, S., Hotchkiss, E. S., \& Song, W. (2011). Do Buyouts (Still) Create Value? Journal of Finance, 66(2), 479-517. https://doi.org/10.1111/ j.1540-6261.2010.01640.x

Howell, S. T. (2017). Financing Innovation: Evidence from R\&D Grants. American Economic Review, 107(4), 1136-1164. https:/doi. org/10.1257/aer.20150808

Jain, B. A., \& Kini, O. (1994). The Post-Issue Operating Performance of IPO Firms. The Journal of Finance, 49(5), 1699-1726. https://doi. org/10.1111/j.1540-6261.1994.tb04778.x

Kaplan, S. (1989). The effects of management buyouts on operating performance and value. Journal of Financial Economics, 24(2), 217254. https://doi.org/10.1016/0304-405X(89)90047-0

Lumpkin, J. R., \& Ireland, R. D. (1988). Screening Practices of New Business Incubators: The Evaluation of Critical Success Factors. American Journal of Small Business, 12(4), 59-81. https://doi. org/10.1177/104225878801200404 
Noked, N. (2014). Integrated tax policy approach to designing research \& development tax benefits. Virginia Tax Review, 34, 109. Retrieved from https://ssrn.com/abstract $=3085443$

OECD. (2018). OECD Review of national R\&D tax incentives and estimates of R\&D tax subsidy rates, 2017 Deliverable 3.3: Summary report on tax subsidy rates - core countries (Year 2) Work package 3. Estimation of implied R\&D tax subsidies. Retrieved from http://www. oecd.org/sti/rd-tax-stats-design-subsidy.pdf

Radas, S., Anić, I.-D., Tafro, A., \& Wagner, V. (2015). The effects of public support schemes on small and medium enterprises. Technovation, 38, 15-30. https://doi.org/10.1016/J.TECHNOVATION.2014.08.002

Rose, G. M., \& Shoham, A. (2002). Export performance and market orientation: establishing an empirical link. Journal of Business Research, 55(3), 217-225. Retrieved from https://ideas.repec.org/a/eee/ jbrese/v55y2002i3p217-225.html
Sauermann, J. (2016). Performance measures and worker productivity. IZA World of Labor. https://doi.org/10.15185/izawol.260

Silva, A. M. (2014). The Determinants of Participation in R\&D Subsidy Programmes: Evidence from Firms and S\&T Organisations in Portugal. Retrieved from https://repositorio-aberto.up.pt/bitstream/10216/77083/2/33266.pdf

Thomson, R. (2012). Measures of R\&D Tax Incentives for OECD Countries. Review of Economics and Institutions, 4(3), 35. https://doi. org/10.5202/rei.v4i3.144

Wiggins, J., \& Gibson, D. V. (2003). Overview of US incubators and the case of the Austin Technology Incubator. International Journal of Entrepreneurship and Innovation Management, 3(1/2), 56. https://doi. org/10.1504/IJEIM.2003.002218 